ARTICLE

Received 6 Feb 2017 | Accepted 11 May 2017 | Published 21 Jun 2017 DOl: 10.1038/ncomms15915

\title{
Munc13-1 and Munc18-1 together prevent NSF-dependent de-priming of synaptic vesicles
}

Enqi He ${ }^{1}$, Keimpe Wierda ${ }^{1, \dagger}$, Rhode van Westen ${ }^{2}$, Jurjen H. Broeke ${ }^{2}$, Ruud F. Toonen ${ }^{1}$, L. Niels Cornelisse ${ }^{2}$ $\&$ Matthijs Verhage ${ }^{1,2}$

Synaptic transmission requires a stable pool of release-ready (primed) vesicles. Here we show that two molecules involved in SNARE-complex assembly, Munc13-1 and Munc18-1, together stabilize release-ready vesicles by preventing de-priming. Replacing neuronal Munc18-1 by a non-neuronal isoform Munc18-2 (Munc18-1/2SWAP) supports activitydependent priming, but primed vesicles fall back into a non-releasable state (de-prime) within seconds. Munc13-1 deficiency produces a similar defect. Inhibitors of $\mathrm{N}$-ethylmaleimide sensitive factor (NSF), $\mathrm{N}$-ethylmaleimide (NEM) or interfering peptides, prevent de-priming in munc18-1/2SWAP or munc13-1 null synapses, but not in CAPS-1/2 null, another primingdeficient mutant. NEM rescues synaptic transmission in munc13-1 null and munc18-1/2SWAP synapses, in acute munc13-1 null slices and even partially in munc13-1/2 double null synapses. Together these data indicate that Munc13-1 and Munc18-1, but not CAPS-1/2, stabilize primed synaptic vesicles by preventing NSF-dependent de-priming.

\footnotetext{
${ }^{1}$ Department of Functional Genomics, Center for Neurogenomics and Cognitive Research, Neuroscience Campus Amsterdam, Vrije Universiteit (VU), Amsterdam 1081HV, The Netherlands. ${ }^{2}$ Department of Clinical Genetics, Center for Neurogenomics and Cognitive Research, Neuroscience Campus Amsterdam, VU Medical Center, Amsterdam 1081HV, The Netherlands. † Present address: VIB Center for the Biology of Disease, Leuven 3000, Belgium; Center for Human Genetics, KU Leuven, 3000 Leuven, Belgium. Correspondence and requests for materials should be addressed to M.V. (email: matthijs@cncr.vu.nl).
} 
$\mathrm{n}$ the mammalian central nervous system, synaptic transmission typically proceeds within milliseconds after incoming action potentials (APs). This property depends critically on the availability of a pool of synaptic vesicles that is immediately available for exocytosis, 'the readily releasable pool (RRP)' or the 'primed' vesicles. Despite intense research, it is currently not known how this primed vesicle pool is made and maintained.

The mammalian SNARE complexes that drive synaptic exocytosis consist of Syntaxin1, Synaptobrevin2 and SNAP25 (refs 1,2). During exocytosis, a four helical bundle is formed in a three step process, involving the N-terminal-, C-terminal and transmembrane areas ${ }^{1,2}$. One hypothesis proposes that primed vesicles have partially zippered trans-SNARE complexes (or 'SNAREpins') between vesicle and plasma membrane where only the $\mathrm{N}$-terminal regions are assembled as a stable, partially assembled intermediate ${ }^{3-5}$. However, plausible alternatives for this model have been suggested ${ }^{3,6}$. Moreover, it is not clear which molecular processes stabilize this proposed partially assembled state, that is, prevent their instant full assembly or their complete disassembly.

Several molecular components have been identified that orchestrate SNARE-complex assembly, stability and disassembly. First, Munc13, Munc18 and CAPS are involved in assembly ${ }^{7-10}$. The number of primed vesicles and the priming rate are regulated by activity $\left(\mathrm{Ca}^{2+}\right)$ and modulatory signals like diacylglycerol and post-translational modifications ${ }^{11}$. Second, $N$-ethylmaleimide sensitive factor (NSF) and $\alpha / \beta S N A P$ disassemble post-fusion cis-complexes $^{12-14}$. Finally, complexins and synaptotagmins have been proposed to prevent premature full assembly of partially assembled SNARE complexes ${ }^{5,15,16}$. However, the molecular factors that prevent disassembly of partially assembled SNARE complexes in primed vesicles (de-priming) are unknown and de-priming remains a poorly characterized process.

Here, we investigated the stability of the primed state and the priming/de-priming balance in mouse hippocampal synapses. We found that primed vesicles are instable in the absence of Munc13-1 or Munc18-1 and fall back into a non-releasable state (de-prime) within seconds. NEM or an NSF-inhibiting peptide prevented this de-priming in synapses that lack Munc13-1 or Munc18-1, but not in CAPS-1/2-deficient synapses. Hereby, preventing de-priming rescued synaptic transmission in munc13-1 null, in synapses where Munc18-1 had been replaced by Munc18-2 and even partially in munc13-1/2 double null synapses.

\section{Results}

Replacing Munc18-1 with -2 produces a munc13-1 KO phenocopy. Previous data suggested that Munc18-1, in addition to its established role in docking/SNARE-complex assembly ${ }^{17-19}$ is also required downstream in the secretion pathway ${ }^{20-22}$. We isolated this aspect of Munc18-1 function, by replacing the endogenous munc18-1 gene in mouse hippocampal neurons with the nonneuronal isoforms Munc18-2 or Munc18-3, by Munc18-2 or -3 expression in munc18-1 null neurons ('munc18-1/2SWAP', 'munc18-1/3SWAP'), and munc18-1 null neurons expressing Munc18-1 (munc18-1/1SWAP) as control. In contrast to munc18-1 null neurons ${ }^{23}$, munc18-1/2SWAP and munc18-1/ 3SWAP neurons are viable and have a normal morphology and synapse density (Supplementary Fig. 1). However, munc18-1/ 2SWAP and munc18-1/3SWAP neurons showed severe defects in basal synaptic transmission: reduced evoked excitatory postsynaptic current (EPSC) amplitude (Fig. 1a,b) and miniature EPSC (mEPSC) frequency, but not-amplitude (Fig. 1c-e). Vesicle docking was largely rescued by Munc18-2, but poorly by Munc18-3 (Fig. 1f-k). Hence, replacing Munc18-1 by Munc18-2 or -3 fully supports neuronal viability but not synaptic transmission.

While basal transmission was severely reduced, 100 APs at $40 \mathrm{~Hz}$ potentiated the evoked EPSC amplitude by $500 \%$ in munc18-1/2SWAP synapses, but not in munc18-1/3SWAP synapses (Fig. 11). This strong potentiation in munc18-1/2SWAP synapses was similar to potentiation previously observed in munc13-1 null glutamatergic synapses ${ }^{7}$ and CAPS-1/2 null synapses ${ }^{10}$. Applying hypertonic sucrose solution to probe the RRP size in munc18-1/2SWAP synapses revealed a sevenfold smaller RRP as compared to control (munc18-1/1SWAP) synapses. A second application of hypertonic sucrose, $3 \mathrm{~s}$ after the first, detected virtually no RRP in contrast to control ${ }^{24}$ (Fig. $1 \mathrm{~m}$ ). However, when $100 \mathrm{AP}$ at $40 \mathrm{~Hz}$ stimulation was applied between the two hypertonic sucrose applications, the RRP detected by the second application was $37 \%$ increased in munc18-1/2SWAP neurons (Fig. 1m,n). This suggests that a stable RRP, but not priming per se, is abolished in munc18-1/2SWAP synapses, as previously concluded for munc13-1 null and CAPS-1/2 null synapses ${ }^{7,10}$. Hence, replacing Munc18-1 by Munc18-2 produces a phenocopy of munc13-1 null and CAPS-1/2 null synaptic phenotype and confirms a post-docking role of Munc18-1 in synaptic transmission that cannot be compensated for by Munc18-2.

Primed vesicles rapidly de-prime without Munc13-1/Munc18-1. The activity-induced potentiation of synaptic transmission in munc18-1/2SWAP synapses was transient, as previously observed for munc13-1 null and CAPS-1/2 null synapses ${ }^{7,10}$. We investigated this transient nature of fusion-competent (primed) vesicles in munc18-1/2SWAP, munc13-1 null and CAPS-1/2 null synapses by single test stimuli at different delays after activity-induced potentiation ('priming train', $100 \mathrm{APs}$ at $40 \mathrm{~Hz}$ ). The largest potentiation of evoked EPSCs was observed $3 \mathrm{~s}$ after priming trains and then decayed (Fig. 2a,b). The time course of this decay was strikingly similar among all three genotypes (Fig. 2b).

To quantify the number of fusion-competent vesicles that disappeared during this decay, we compared the total number of vesicles released by 10 stimuli at different intervals after priming trains in munc18-1/2SWAP and munc13-1 null synapses. We subtracted the total charge induced by 10 stimuli $45 \mathrm{~s}$ after priming trains from the total change at $10 \mathrm{~s}$ after priming trains (Fig. 2c, see Experimental procedures for details). In addition to this $10-45 \mathrm{~s}$ interval, we also analysed the $3-30 \mathrm{~s}$ interval (Supplementary Fig. 2a-e). These comparisons revealed that very few vesicles that were fusion-competent shortly after priming trains ( 3 or $10 \mathrm{~s}$ after the train), were still fusion-competent after 30 or 45 s (Fig. 2d,e and Supplementary Fig. 2a-e). This loss of fusion-competent vesicles cannot be explained by spontaneous release. Spontaneous release is known to be increased after 100 APs at $40 \mathrm{~Hz}$, but the total spontaneous release during the $35 \mathrm{~s}$ interval between the 10 and $45 \mathrm{~s}$ time points was only $27 \%$ of the synchronous (evoked) release lost between these time points (Fig. 2f,g). We also tested these protocols in wild-type (WT) neurons and neurons over-expressing NSF. No evidence for de-priming was observed in these cases (Supplementary Fig. $3 \mathrm{a}-\mathrm{d})$. This suggests that the majority of the vesicles primed by AP-trains, de-primed in in munc18-1/2SWAP and munc13-1 null synapses, but not in WT neurons or neurons over-expressing NSF.

We also assessed the total pool of releasable vesicles with a $\mathrm{Ca}^{2+}$-independent method, using hypertonic sucrose to exclude contributions of $\mathrm{Ca}^{2+}$-dependent priming during AP-trains on our estimate of fusion-competent vesicles (Supplementary 
a

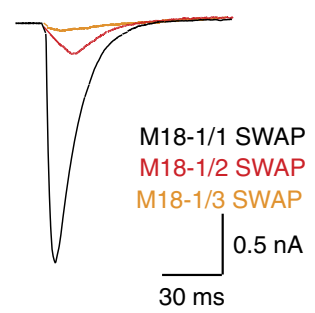

f

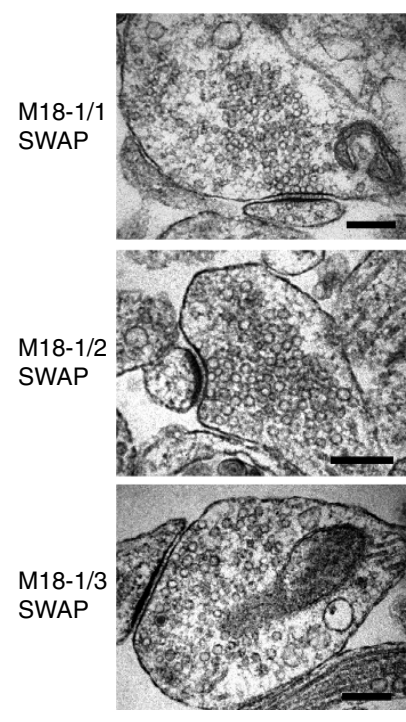

b

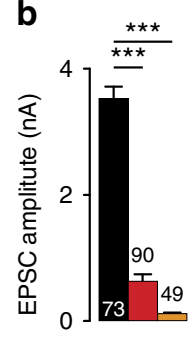

g Docked vesicles

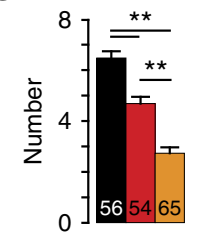

h

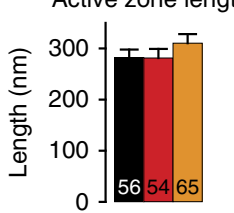

i Total vesicle number

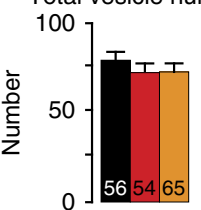

c

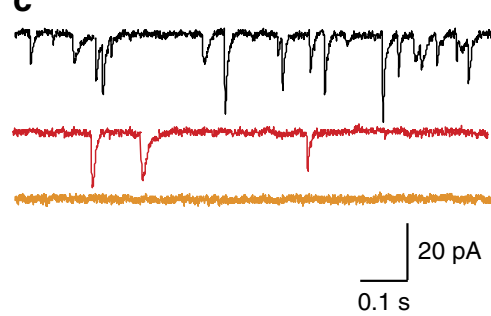

d

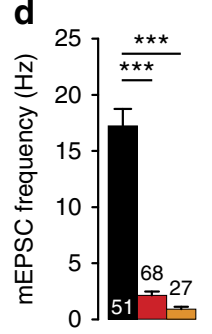

e

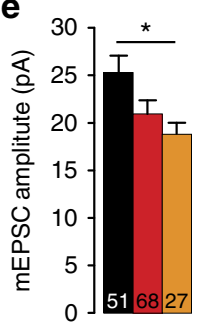

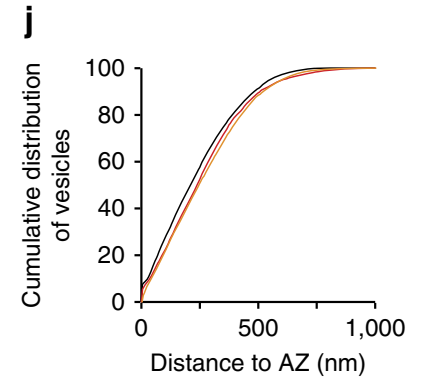

$\mathbf{k}$

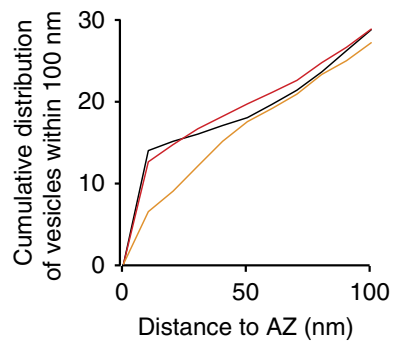

I
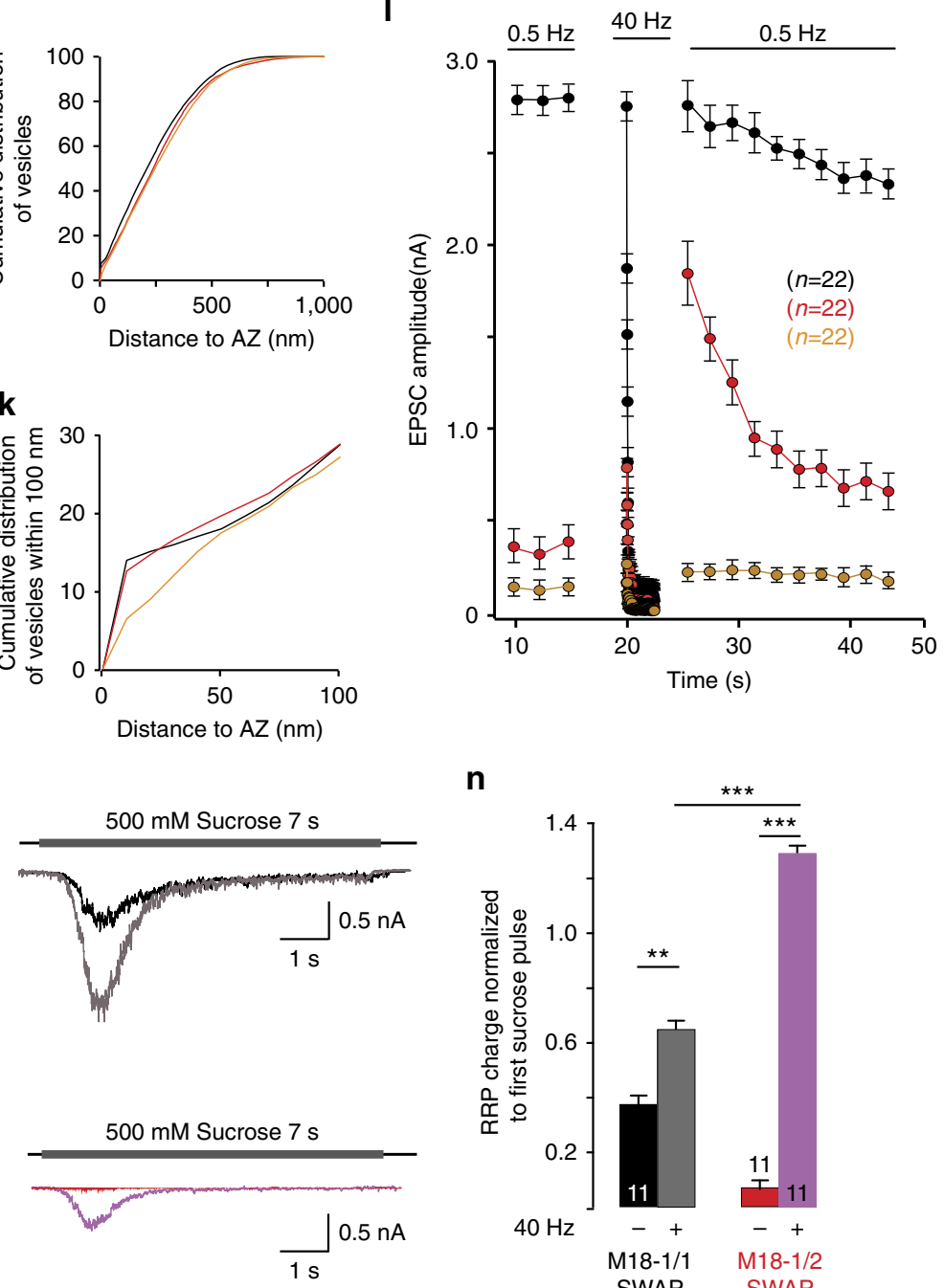

n

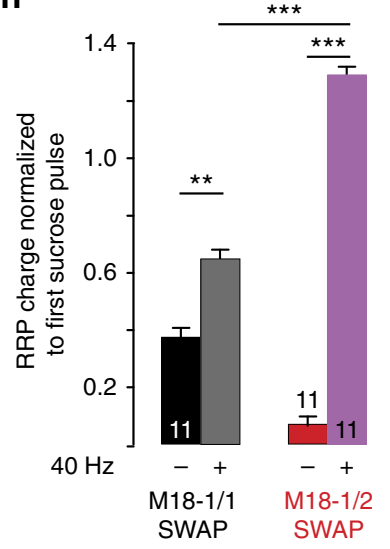

Figure 1 | Replacing Munc18-1 with Munc18-2 but not Munc18-3 produces a munc13-1 null phenocopy. (a,b) Sample traces and quantification of evoked EPSCs in naive munc18-1/1SWAP, munc18-1/2SWAP and munc18-1/3SWAP neurons. (c-e) Mini EPSCs sample traces (c), and quantification of frequency (d) and amplitudes (e). (f-k) Ultrastructural analysis of munc18-1/1SWAP, munc18-1/2SWAP and munc18-1/3SWAP asymmetric (glutamatergic) synapses: sample electron micrographs; scale bar, $100 \mathrm{~nm},(\mathbf{f})$ and quantification of docked vesicles $(\mathbf{g})$, active zone length (h) and total vesicle number (i); cumulative plot of vesicle distance from the active zone (j) and a zoom of the first $100 \mathrm{~nm}(\mathbf{k})$. (I) Synaptic run down during $100 \mathrm{AP}$ at $40 \mathrm{~Hz}$ and transient potentiation of synaptic transmission in munc18-1/2SWAP, but not the other genotypes. ( $\mathbf{m}, \mathbf{n})$ Assessment of activity-dependent priming using application of hypertonic sucrose to probe the readily releasable vesicle pool: sample traces $(\mathrm{m})$ of munc18-1/2SWAP (red/blue) and control (munc18-1/1SWAP, black/grey) neurons stimulated with $500 \mathrm{mM}$ sucrose twice with a $3 \mathrm{~s}$ interval with (grey/bleu) or without (black/red) $100 \mathrm{AP}$ at $40 \mathrm{~Hz}$ during this interval; (n) quantification of total charge generated by second hypertonic sucrose pulses, normalized to the first pulse. All data in this figure are means \pm s.e.m.; ${ }^{\star} P<0.05$, ${ }^{\star \star} P<0.01$, ${ }^{\star * \star} P<0.001$ as determined by ANOVA. See Supplementary Table 1 for all values, s.e.m. and $n$-numbers plotted in this figure. ANOVA, analysis of variance.

Fig. 2f). Thirty seconds after priming trains, the reduction in sucrose-evoked responses was comparable with the reduction in AP-evoked responses (compare Supplementary Fig. $2 \mathrm{~g}$ with 2c), and much larger than the loss of vesicles through spontaneous release (Supplementary Fig. 2d,e,h,i). Hence, fusion-competent vesicles that contributed to synaptic transmission shortly after priming trains, no longer did so after 30 or $45 \mathrm{~s}$ in the absence of Munc13-1 or Munc18-1. This confirms that the majority of the vesicles primed by AP-trains, de-primed in the absence of these molecules. 

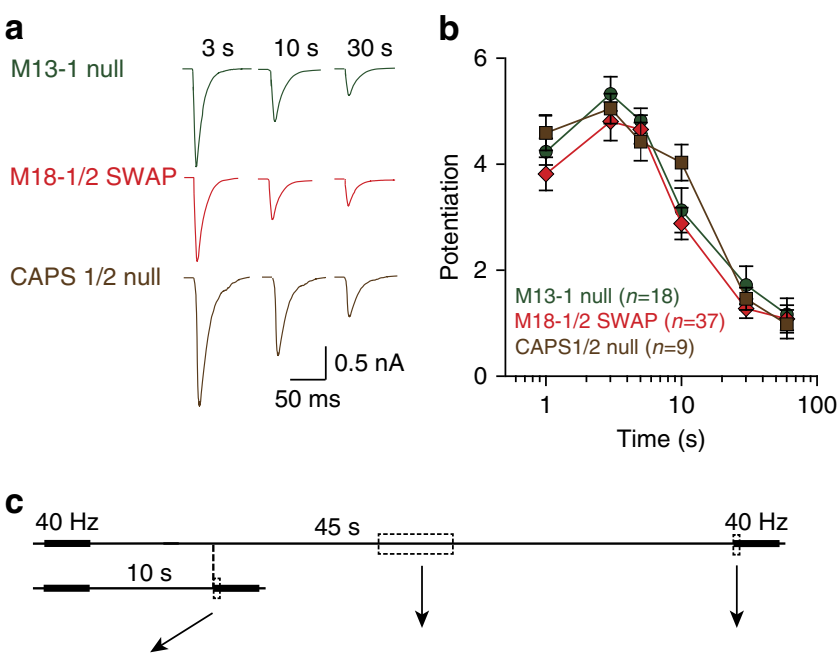

d

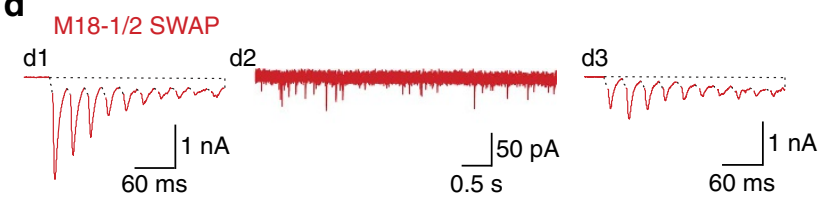

e
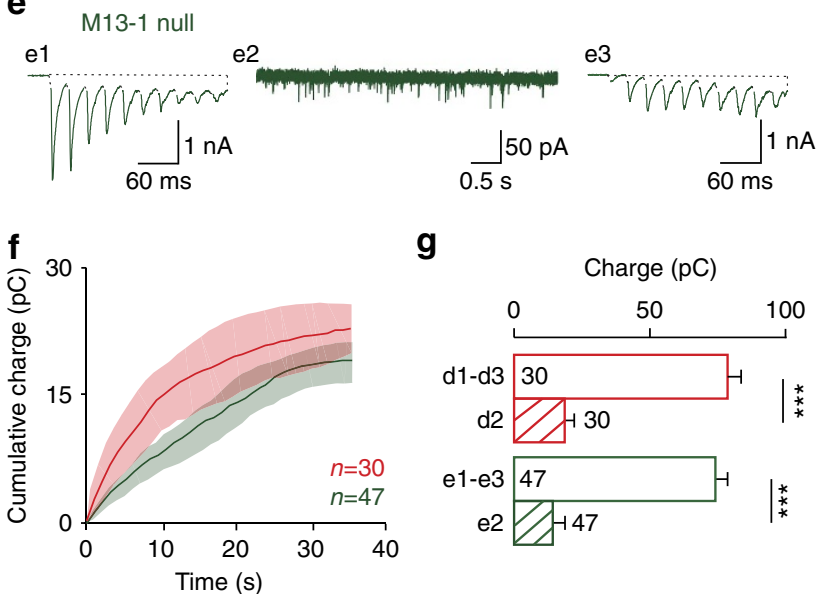

g

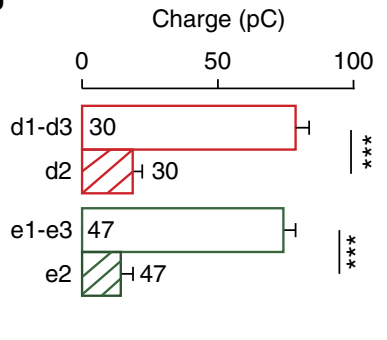

Figure 2 | Primed vesicles rapidly de-prime in the absence of Munc13-1 or Munc18-1. (a) Sample traces of evoked EPSCs following 3, 10 and $30 \mathrm{~s}$ after a priming train (100AP at $40 \mathrm{~Hz}$ ). (b) Similar time course of activitydependent potentiation in munc18-1/2SWAP, munc13-1 null and CAPS- $1 / 2$ null synapses. (c) Paradigm to assess de-priming (see Methods for details). (d,e) sample traces of dual $100 \mathrm{AP}$ at $40 \mathrm{~Hz}$ with 10 or $45 \mathrm{~s}$ interval in munc18-1/2SWAP (d) and munc13-1 null (e) synapses. (f) Spontaneous fusion events were quantified for the $10-45 \mathrm{~s}$ intervals. (g) To quantify de-priming, the total charge of the first 10 responses (d1, d3; e1, e3) of each stimulus train was quantified. The spontaneous fusion of vesicles in the $10-45 \mathrm{~s}$ intervals (d2; e2) cannot explain the loss of fusion-competent vesicles after $45 \mathrm{~s}$, defined as the difference in total charge between 10 and $45 \mathrm{~s}$ intervals (d1-d3; e1-e3). All data in this figure are means \pm s.e.m., ${ }^{\star \star \star} P<0.001, P$ value are determined by Wilcoxon signed rank test; the de-priming was also observed with 3-30 s intervals (Supplementary Fig. 2).

NSF-inhibition rescues de-priming defects. One current working model proposes that in the primed state, a trans-SNAREcomplex is already established 'loosely ${ }^{25}$ or 'partially'26,27. Therefore, we hypothesized that de-priming observed in the munc18-1/2SWAP, munc13-1 and CAPS-1/2 null synapses involves trans-SNARE-complex disassembly. To test this, we applied $N$-ethylmaleimide (NEM), a generic NSF inhibitor, and specific NSF-interfering peptides in munc13-1 null, munc18-1/ 2SWAP and CAPS-1/2 null synapses.

Within $10 \mathrm{~s}$ after NEM application, the small initial EPSC of munc13-1 null synapses was potentiated nearly 500\%, to a similar extent as high-frequency stimulation (Fig. 3a,b), and the potentiation is time- and dose-dependent (Supplementary Fig. 4c,d). The mEPSC frequency also increased, by $250 \%$, with no significant change in mEPSC amplitude (Fig. 3c,d). In munc18-1/2SWAP synapses, a similar potentiation of evoked and spontaneous release was observed (Fig. 3e,f). Strikingly, NEM did not potentiate synaptic transmission in CAPS-1/2 null synapses (Fig. 3g,h). This lack of effect in CAPS-1/2 null synapses confirms that NEM does not rescue priming-deficient synapses by elevating the cellular calcium concentration (as $40 \mathrm{~Hz}$ stimulation does). Furthermore, NEM did not potentiate synaptic transmission in WT neurons (Supplementary Fig. 4a,b), ruling out nonspecific enhancement of transmission, unrelated to de-priming.

The effect of NEM on synaptic transmission in munc13-1 null synapses built up during the first seconds after NEM application, was highest $10-60 \mathrm{~s}$ after application, lasted far beyond activityinduced potentiation and then decayed (Fig. $3 \mathrm{i}$ and Supplementary Fig. 4c-f). This final decay can be explained by inhibition of NSF's established role in cis-SNARE disassembly and recycling (and/or to reactivate release sites). Taken together, these data show that NSF-inhibition prevents de-priming in munc18-1/2SWAP and munc13-1 null synapses, but not in CAPS-1/2 null synapses, and restored their ability to generate near-normal EPSCs upon stimulation.

In contrast to munc13-1 null synapses, munc13-1/2 double null synapses lack all synaptic activity ${ }^{28}$. Remarkably, after NEM application to munc13-1/2 null synapses single test stimuli now produced a small EPSC (Fig. 3j,k). NEM did not produce similar effects in mutants known to produce more upstream defects in the secretory pathway, munc18-1 conditional null and syntaxin-deficient (BoNT-C treated) synapses (Fig. 31,m). Hence, synapses deficient for proteins that act upstream of priming (that is, tethering/docking) are not rescued by NSF-inhibition, but NSF-inhibition in munc13-1/2 double null synapses reveals synaptic vesicles prime in the absence of Munc13-1 and Munc13-2.

To obtain independent proof for the role of NSF in de-priming, we tested specific NSF (peptide) blockers ${ }^{13,29}$. Peptide loading via the patch pipette for $30 \mathrm{~min}$ or application of cell membrane permeable peptide (TAT-NSF peptide ${ }^{30}$, potentiated EPSCs in munc13-1 null synapses, similar to NEM (Fig. 4a-d). The enhancement of synaptic transmission was more variable than NEM application, probably due to the slow and incomplete loading of the peptide into synapses. Peptide loading, via the pipette or using the TAT-tag, is inherently slower than NEM application. On this slower timescale it is not possible to completely separate de-priming inhibition from inhibition of NSF's established role in cis-SNARE disassembly and recycling (and/or to reactivate release sites). However, both approaches yielded robust significant enhancement of synaptic transmission in mutant synapses confirming that NSF-inhibition prevents de-priming.

$\mathrm{N}$-ethylmaleimide enhances activity in munc13-1 null networks. To confirm that de-priming in the absence of Munc13-1 also occurs in intact neural networks, we tested NEM in acute hippocampal slices of newborn munc13-1 null mice. At birth, the hippocampal synaptic network is still developing, many synapses are electro-physiologically silent and little evoked activity can be recorded $^{31,32}$. However, spontaneous activity can be detected, also 

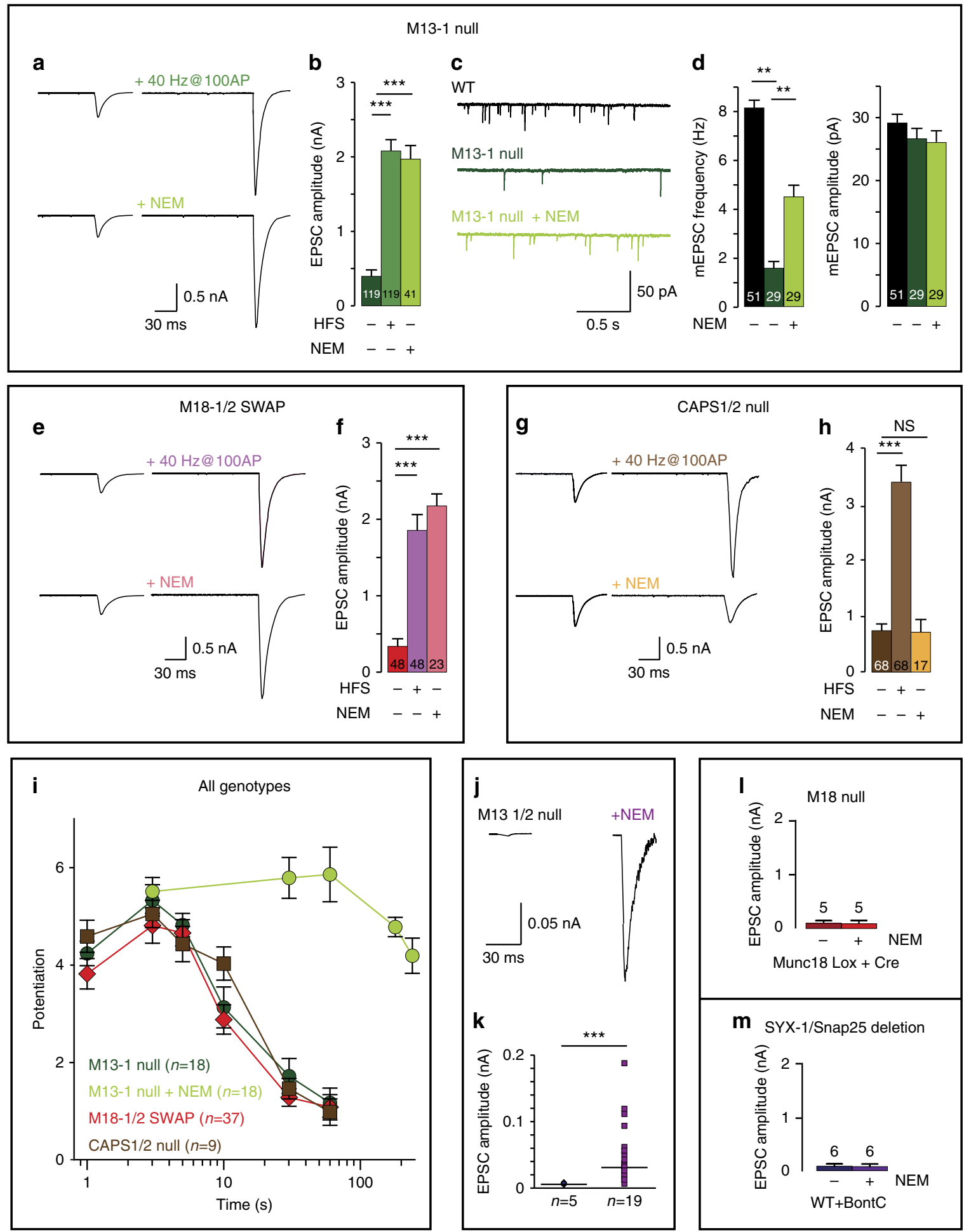

Figure 3 | NSF-inhibition prevents de-priming and restores synaptic transmission in munc18-1/2SWAP and munc13-1 null. (a,b) Sample traces and quantification of EPSCs potentiated by $100 \mathrm{AP}$ at $40 \mathrm{~Hz}$ or $10 \mathrm{~s}$ NEM application (100 $\mu \mathrm{M}$ ) in munc13-1 null synapses. (c,d) mEPSCs sample traces and quantification of frequency and amplitude. (e,f) Sample traces and quantification of EPSCs potentiated by $100 \mathrm{AP}$ at $40 \mathrm{~Hz}$ or $10 \mathrm{~s}$ NEM application $(100 \mu \mathrm{M})$ in munc18-1/2SWAP synapses. (g,h) Sample traces and quantification of EPSCs potentiated by $100 \mathrm{AP}$ at $40 \mathrm{~Hz}$ or $10 \mathrm{~s}$ NEM application (100 $\mu \mathrm{M})$ in CAPS-1/2 null synapses. (i) Comparison of effectiveness between $100 \mathrm{AP}$ at $40 \mathrm{~Hz}$ or $10 \mathrm{~s}$ NEM application on potentiation of synaptic transmission in all genotypes. Data on 100AP at $40 \mathrm{~Hz}$ stimulation are copied from Fig. 2a for comparison. (j,k) Sample traces and quantification of EPSCs in munc13-1/2 null neurons with/without 10 s NEM application; (I) quantification of EPSCs in Cre-expressing munc18-1 lox neurons with and without NEM application. (m) Quantification of EPSCs in BoNT-C infected WT neurons with and without NEM application. All data in this figure are means \pm s.e.m. In $\mathbf{b}, \mathbf{d}, \mathbf{f}, \mathbf{h}$, ${ }^{\star} P<0.05,{ }^{\star \star} P<0.01,{ }^{\star \star \star} P<0.001$, are determined by ANOVA; in $\mathbf{k}, P$ values are determined by a binomial test. See Supplementary Table 1 for all values, s.e.m. and $n$-numbers plotted in this figure. ANOVA, analysis of variance. 

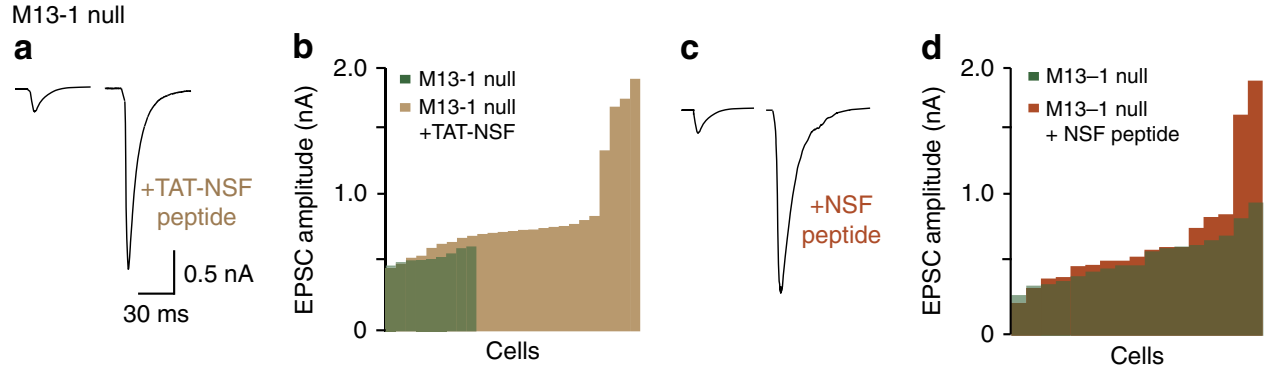

Figure 4 | NSF-specific blockers restore synaptic transmission in munc13-1 null synapses. (a,b) Sample traces and histogram of EPSCs in munc13-1 null neurons with and without application of TAT-tagged NSF inhibitor peptide. (c,d) Sample traces and histogram of EPSCs in munc13-1 null neurons with or without application of NSF-inhibiting peptide through the pipette. $P$ values are determined by binomial test, ${ }^{\star \star \star} P<0.001$.

a

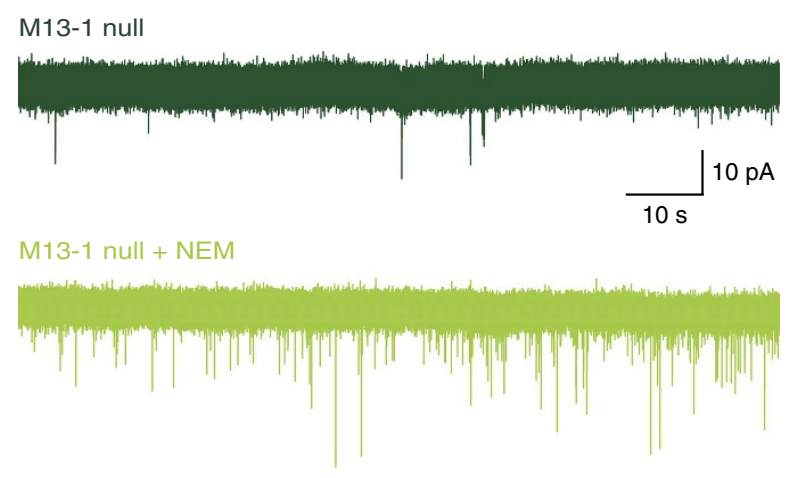

b

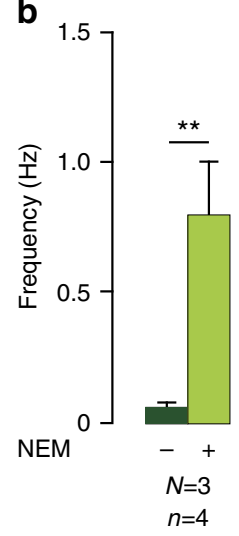

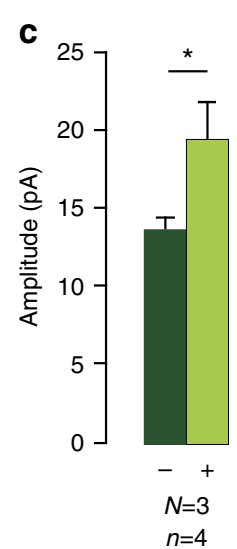

Figure 5 | Potentiation of synaptic responses by NSF-inhibition in acute brain slices. (a) Sample traces of spontaneous activity in immature synapses of newborn hippocampal slices of munc13-1 null mice with/without NEM $(100 \mu \mathrm{M})$. (b,c) Quantification of mEPSC frequency and amplitude, $N=3, n=4$. Data in this figure are means \pm s.e.m. ${ }^{\star} P<0.05,{ }^{\star \star} P<0.01, P$ value are determined by paired $t$-test.

in munc13-1 null slices (Fig. 5a). NEM application increased spontaneous activity by more than $700 \%$ (Fig. 5a,b), that is, a larger increase than observed in cultured neurons $(<300 \%$, compare Figs $3 \mathrm{~d}$ and $5 \mathrm{~b}$ ). NEM also produced a moderate increase in the amplitude of spontaneous events in these developing networks (Fig. 5c). These data confirm that NSF-inhibition prevents de-priming in munc13-1 null synapses also in acute ex vivo preparations.

\section{Discussion}

This study shows that Munc13-1 and Munc18-1, in addition to their established role in docking/priming vesicles for fusion, prevent de-priming. Without this aspect of Munc13/18 function, synapses are very weak and activity can potentiate synaptic transmission only transiently. This suggests that de-priming is an important aspect of the synaptic vesicle cycle. Preventing de-priming is a crucial aspect of synaptic transmission.

The established (forward) role of Munc13-1 and Munc18-1 in docking/priming is shared with other isoforms, Munc13-2 and Munc18-2, and these isoforms rescue docking/priming in the absence of Munc13-1 and Munc18-1. However, the ability to inhibit de-priming is specific for the synaptic isoforms, Munc13-1 and Munc18-1, suggesting this function is an evolutionary adaptation that helps synapses to build stable reservoirs of fusion-ready vesicles to sustain high-frequency transmission. Our data suggest that Munc13-1 and Munc18-1 are both required to prevent de-priming (Fig. 6a), probably by acting in tandem.
This is consistent with their concerted actions in synaptic plasticity 21,33 . The fact that synaptic transmission is largely rescued by acute NSF-inhibition in munc13-1 null synapses suggests that de-priming inhibition is a major aspect of Munc13-1 function.

Our findings are in line with kinetic schemes considering the RRP as a dynamic equilibrium between priming and de-priming rates $^{34,35}$.The RRP is generally defined as the pool of vesicles having a release probability $>0$. However, substantial heterogeneity exists among vesicles in the RRP and activity and/or modulatory signals change the likeliness that a given vesicle fuses upon a given $\mathrm{Ca}^{2+}$-increase (fusogenicity), probably due to modulation of the energy barrier for fusion ${ }^{36,37}$. It is already well documented that a $\mathrm{Ca}^{2}{ }^{+}$-dependent increase in the forward priming rate and presynaptic modulators such as diacylglycerol promote fusogenicity (and in some cases also the RRP size), and induce synaptic plasticity ${ }^{21,33,36,38}$. Plausible mechanisms for this modulation are an increase in the number of SNARE-complexes (partially) assembled per vesicle ${ }^{37,39}$ or an increased efficiency of the fusion machinery, such as Munc13s (refs 38,40,41). In addition to the regulation of the forward priming rate, we now present evidence that de-priming is also regulated by presynaptic proteins. We show that regulation of de-priming also regulates fusogenicity and RRP size in an equilibrium with forward priming rates. This idea is in line with observations in chromaffin cells, where the RRP scales with basal calcium and transiently facilitates (overshoots) after stimulation ${ }^{42}$. This suggests a high de-priming rate, causing a 
a

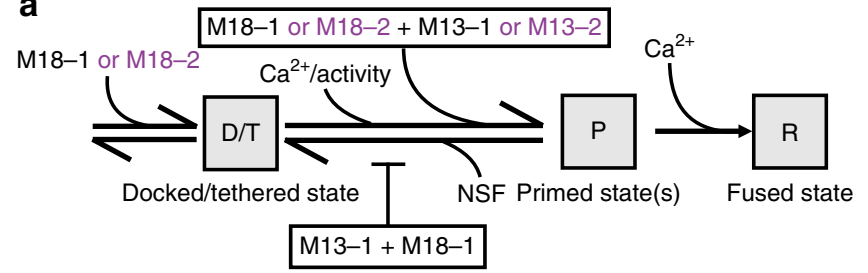

b
\begin{tabular}{|l|c|c|c|c|} 
Cell viability & \multicolumn{1}{c}{$\begin{array}{c}\text { Tethering/ } \\
\text { docking }\end{array}$} & Priming & $\begin{array}{c}\text { Prevent } \\
\text { de-priming }\end{array}$ \\
\hline Munc18-1 & +++ & +++ & +++ & +++ \\
\hline Munc18-2 & +++ & ++ & +++ & - \\
\hline Munc18-3 & +++ & + & - & - \\
\hline
\end{tabular}

Figure 6 | Working model for how Munc13-1 and Munc18-1 prevent NSF-dependent de-priming and comparison of the function of Munc13/18 isoforms in the secretory pathway (a) Flow chart working model of the proposed actions of Munc13, Munc18 in the secretory pathway. Dominant isoforms are depicted in black and non-dominant/heterologous isoforms in purple. (b) Summary of proposed (non-) redundancy of cellular functions among Munc18 isoforms 1, 2 and 3 on cell viability, vesicle tethering/ docking, priming, prevent de-priming. Number of + indicates to what extent a given isoform supports a given function, where +++ is full support and - indicates no support.

relatively low RRP size under resting, low $\mathrm{Ca}^{2+}$ conditions, which shifts (temporarily) to a larger RRP when calcium levels are higher. Furthermore, a similar mechanism was suggested in general models for short-term plasticity observed in crayfish neuromuscular junctions and hippocampal- and cerebellar mossy fibre boutons $\mathrm{s}^{35,43}$. Strikingly, in this model ${ }^{35}$, the de-priming rate is the only parameter that is different between depressing 'phasic' synapses and facilitating 'tonic' synapses ${ }^{35,44}$. This theoretical prediction fits very well with the switch from depression to facilitation demonstrated here by increasing de-priming in M18-1/2SWAP and Munc13-1 KO neurons and also with the fact that NEM application produces a (mild) potentiation of synaptic transmission in mammalian neuromuscular junctions ${ }^{45-47}$. In these synapses, vesicles still fuse in the absence of Munc13-1/2, but there is no stable RRP ${ }^{48}$. Hence, expression of specific Munc13- (and possibly also Munc18-) isoforms probably defines de-priming rates in synapses and hereby their depressing or facilitating properties. Indeed, differential expression of Munc13-2 in basolateral amygdala synapses is responsible for a shift in facilitation versus depression ${ }^{49}$. However, dentate gyrus mossy fibre synapses that prominently express Munc13-2, but in this case also Munc13-1, become even more facilitating upon deletion of Munc13-2 expression ${ }^{50}$. This remains a puzzling observation, especially why Munc13-1 expression does not lead to a higher initial release probability in these synapses. The ability of Munc13-1 to inhibit de-priming may depend on other molecules, such as RIM, RIM-BPs and ELKS. Deletion of RIM and RIM-BP switches depressing synapses to facilitation, expression of a RIM mutant that specifically lacks Munc13-1 binding/activation shows facilitation ${ }^{51-54}$ and ELKS1 specifically localizes Munc13-2 to specific active zones and determines facilitation/depression properties ${ }^{55}$.

To obtain experimental evidence for the role of NSF in de-priming, required acute inhibition of NSF. During chronic inhibition, for example, shRNA knockdown, the canonical function of NSF in regenerating cis-SNARE complexes throughout the cell prevails and neurons die within a few days (Supplementary Fig. 5a). The main evidence for a role of NSF in de-priming in this study comes from the use of NEM, an alkene reactive towards thiols that modifies cysteines in cellular proteins with little selectivity. Therefore, NEM may have nonspecific effects in addition to its established inhibition of NSF. However, at least five arguments suggest that such potential nonspecific effects do not confound our conclusions on the role of NSF in de-priming. First, NEM does not rescue synaptic transmission in CAPS-1/2 null synapses, which are equally weak as munc13-1 null synapses $^{10}$ and can, like munc13-1 null and munc18-1/2SWAP synapses, also be rescued by trains of APs. Hence, NEM does not simply promote activity or increase intracellular $\mathrm{Ca}^{2+}$ to rescue munc13-1 null and munc18-1/2SWAP synapses. Second, the rescue effect of NEM lasts much longer than activity/ $\mathrm{Ca}^{2+}$-increases (Fig. 3i and Supplementary Fig. 4e-h). Third, NEM does not promote synaptic transmission in WT synapses (Supplementary Fig. 4a), Fourth, NEM does not rescue synapses with more upstream defects, that is, BoNT-C treated or munc18-1 null synapses (Fig. 31,m). Finally, NSF-inhibition using independent approaches, using a specific inhibitory peptide, also rescues munc13-1 null and munc18-1/2SWAP synapses. Together, these findings confirm the specificity of this generic inhibitor.

The replacement experiments (munc18-1/2SWAP) help to define Munc18-1's post-docking role. The previously described role of Munc18-1 in the initial vesicle docking/tethering, upstream of SNARE-complex formation ${ }^{17,19}$, can largely be covered by Munc18-2 expression as proposed before ${ }^{20}$. The fact that the munc18-1/2SWAP produces a munc13-1 phenocopy now suggests that Munc18 acts in tandem with Munc13 to prime vesicles. Together these findings suggest that the elusive positive function of Munc18 in the vesicle cycle consist of (i) promoting docking/tethering, (ii) promoting priming in tandem with Munc13s and (iii) preventing de-priming (Fig. 6a). The first two aspects of Munc18-1 function can be covered by Munc18-2, the latter cannot. Expression of the more distant isoform, Munc18-3, in munc18-1 null neurons rescued cell viability, but not priming (in contrast to Munc18-2). This suggests that the role of Munc18-1 in cell viability is yet another distinct aspect of this pivotal molecule and that the three isoforms support these different aspects to a different extent (Fig. 6b).

Whether $\alpha$ SNAP/NSF act on trans-SNARE complexes has been subject of long debate ${ }^{56}$. Our study provides two lines of evidence, using the generic blocker NEM and specific interfering peptides that they indeed do. The fact that Munc13-1 and Munc18-1 prevent NSF from de-priming primed vesicles may explain why neuronal trans-SNARE-complexes in situ were found to be NSF-resistant.

\section{Methods}

Laboratory animals. Munc18-1 null and CAPS-1/2 null mice were generated as described before ${ }^{10,23}$ and maintained on a C57BL/6J background after $>20$ (CAPS-1/2) or $>40$ (munc18-1) generations of backcrossing. Munc13-1 null, and Munc13-1/2 null mice were produced as described previously ${ }^{28,57}$ and maintained on a FVB/NHan background. All neurons were obtained from E18 embryos of all sexes by caesarean sections of pregnant females from timed heterozygous matings. Animals were housed and bred according to institutional and Dutch governmental guidelines, and all procedures are approved by the ethical committee of the Vrije Universiteit, Amsterdam, The Netherlands.

Neuronal cultures and lentiviral transduction. Hippocampi and cortices were separately collected in ice-cold Hanks Buffered Salt Solution (HBSS; Sigma) buffered with $1 \mathrm{mM}$ HEPS (Invitrogen). After removal of the meninges, tissue was incubated in Hanks-HEPES with $0.25 \%$ trypsin (Invitrogen) for $12 \mathrm{~min}$ at $37^{\circ} \mathrm{C}$. After washing, the tissues were triturated and counted in a Fuchs-Rosenthal chamber. Neurons were plated in pre-warmed Neurobasal medium (Invitrogen) supplemented with 2\% B-27 (Invitrogen), 1.8\% HEPES, $0.25 \%$ glutamax 
(Invitrogen) and $0.1 \%$ Pen/Strep (Invitrogen). To achieve autaptic cultures, hippocampal neurons were plated at a density of $6 \mathrm{~K}$ per well of a 12 -well plate on micro-islands of rat glia on ultraviolet-sterilized agarose-coated etched glass coverslips stamped with a $0.1 \mathrm{mg} \mathrm{ml}^{-1}$ poly-D-lysine (Sigma) and $0.2 \mathrm{mg} \mathrm{ml}^{-1}$ rat tail collagen (BD biosciences) solution ${ }^{58}$. Network cultures were generated by plating cortical neurons $(10-25 \mathrm{~K}$ per well on a 12 -well plate) on a confluent layer of rat glia grown on etched glass coverslips sprayed with a $0.1 \mathrm{mg} \mathrm{ml}^{-1}$ poly-D-lysine (Sigma) and $0.2 \mathrm{mg} \mathrm{ml}^{-1}$ rat tail collagen (BD biosciences) solution. Neurons were infected at DIV0 with lentiviral particles encoding Munc18-1, Munc18-2 and Munc18-3 (ref. 21), and were allowed to develop for 13-18 days before measuring. For NSF knockdown experiments, the shRNA targeting mouse NSF was obtained from Amsterdam Medical Center (TRCN0000101667, Sigma Aldrich) and cloned into the same lentiviral backbone as the Munc18 cDNAs (see above). A knockdown-resistant NSF variant was developed by introducing silent mutations in the mouse NSF cDNA ( $5^{\prime}$-ccc ggg cgc ttg gaa gtt aaa- $\left.3^{\prime}\right)$ and cloned into lentiviral backbone.

Electron microscopy. Autaptic hippocampal cultures obtained from three different litters were fixed at DIV14-16 for $45 \mathrm{~min}$ at room temperature with $2.5 \%$ glutaraldehyde in $0.1 \mathrm{M}$ cacodylate buffer $(\mathrm{pH} 7.4)^{19,21}$. Only glia islands containing a single neuron were used for analysis. After fixation cells were washed three times for $5 \mathrm{~min}$ with $0.1 \mathrm{M}$ cacodylate buffer ( $\mathrm{pH} 7.4$ ), post-fixed for $2 \mathrm{~h}$ at room temperature with $1 \%$ osmium tetroxide/ $1 \%$ potassium ferrocyanide in double distilled water, washed and stained with $1 \%$ uranyl acetate for $40 \mathrm{~min}$ in the dark. Following dehydration through a series of increasing ethanol concentrations, cells were embedded in Epon and polymerized for $24 \mathrm{~h}$ at $60^{\circ} \mathrm{C}$. After polymerization of the Epon, the coverslip was removed by alternately dipping it in liquid nitrogen and hot water. Cells of interest were selected by observing the flat Epon-embedded cell monolayer under the light microscope, and mounted on pre-polymerized Epon blocks for thin sectioning. Ultrathin sections $(\sim 80 \mathrm{~nm})$ were cut parallel to the cell monolayer and collected on single-slot, formvar-coated copper grids, and stained in uranyl acetate and lead citrate. Autaptic synapses were selected at low magnification using a JEOL 1010 electron microscope. All analyses were performed on single ultrathin sections of randomly selected synapses. The distribution of synaptic vesicles, total synaptic vesicle number and active zone length were measured with Image J (National Institute of Health, USA) on digital images of synapses taken at $\times 80,000$ magnification using analySIS software (Soft Imaging System, GmbH, Germany). The observer was blinded for the genotype. For all morphological analyses we selected only synapses with intact synaptic plasma membranes with a recognizable pre- and postsynaptic density and clear synaptic vesicle membranes. Docked synaptic vesicles had a distance of $0 \mathrm{~nm}$ from the synaptic vesicle membrane to the active zone membrane. The active zone membrane was recognized as a specialized part of the presynaptic plasma membrane that contained a clear presynaptic density.

Electrophysiology of autaptic neurons. Whole-cell recordings were performed using an Axopatch 200B amplifier (Molecular Devices) at room temperature. Digidata 1440 and Clampex 10.0 (Molecular Devices) were used for data acquisition. The external solution contained the following (in mM): $140 \mathrm{NaCl}$ $2.4 \mathrm{KCl}, 4 \mathrm{MgCl}_{2} 4 \mathrm{CaCl}_{2}, 10$ HEPES and 10 glucose $(\mathrm{pH}=7.30,300 \mathrm{mOsmol})$. Patch pipette solution contained the following (in $\mathrm{mM}$ ): $125 \mathrm{~K}^{+}$-gluconic acid, 10 $\mathrm{NaCl}, 4.6 \mathrm{MgCl}_{2}, 15$ creatine phosphate, $10 \mathrm{U} \mathrm{ml}^{-1}$ phosphocreatine kinase and 1 EGTA ( $\mathrm{pH} 7.30$ ). Only cells with an access resistance of $<10 \mathrm{M} \Omega$ and leak current of $<300 \mathrm{pA}$ were accepted for analysis. The recorded was compensated to $60 \%$. The RRP size was determined by a rapid switch to external saline solution made hypertonic by the addition of $0.5 \mathrm{M}$ sucrose for $7 \mathrm{~s}$ (ref. 37). All analyses were performed using Clampfit 10.2, MiniAnalysis (Synaptosoft) and custom-written software routines in Matlab R2010a. In AP-induced EPSC's, the stimulation artefact was removed and interpolated using cubic interpolation. The baseline for synchronous charge is determined by a straight line between the starting point of response $r$ and the starting point of response $r+1$. NEM (Sigma) was added to external solution at various concentrations $(50,100,200,500,1,000 \mu \mathrm{M})$. NSF blocking peptide (Tebu-Bio) was loaded intracellularly via the patch pipette. The tat-NSF peptides were added to the cell media and incubated with neurons in the incubator for $15 \mathrm{~min}$.

To measure the stability of activity-dependent primed vesicles, the number of primed vesicles at different delays after activity-induced potentiation was compared. To achieve this, evoked EPSCs were measured after test trains $(100 \mathrm{AP}$ at $40 \mathrm{~Hz})$ with variable delay after activity-dependent priming by a priming train (also 100AP at $40 \mathrm{~Hz}$ ). We compared two intervals: (a) 3 versus $30 \mathrm{~s}$ after the priming train and (b) 10 versus $45 \mathrm{~s}$ after the priming train. The assessment of responses $3 \mathrm{~s}$ after the priming train was complicated by remaining asynchronous release resulting from the preceding priming train. Therefore the comparison $10-45 \mathrm{~s}$ was used in the main text and the comparison $3-30 \mathrm{~s}$ is shown as Supplementary Data. Potentiation of evoked release after the priming train was restricted to the first 10 EPSC, presumably because these are dominated by synchronous release that draws directly from the established RRP after the priming train, whereas asynchronous release also includes newly primed vesicles which becomes dominant in later responses. Therefore, we included only the charge of the first 10 EPSCs when comparing the pool of primed vesicles (expressed in $\mathrm{nC}$ ) at different intervals after the priming train (10 versus 45 and 3 versus 30 ). Furthermore, to quantify the number of vesicles that fused spontaneously during the test intervals, the spontaneous release charge was quantified between the two time points (10 versus 45 and 3 versus 30 ). The charge of each event was assessed by subtracting the baseline from the trace. The baseline was determined every $100 \mathrm{~ms}$ as the midline of the noise. To avoid any confounding effect of activity-dependent priming on RRP estimation we performed an independent set of experiments where we used hypertonic sucrose $(500 \mathrm{mM}$, see above) to measure the pool of primed vesicles 3 and $30 \mathrm{~s}$ after a priming train. De-priming was quantified by integrating the current obtained by subtracting the response at $30 \mathrm{~s}$ from the response at $3 \mathrm{~s}$ after the priming train.

Preparation of acute slices. Acute coronal slices were obtained from newborn (P0) mice. Brains were rapidly removed after decapitation and placed into ice-cold choline solution $(110 \mathrm{mM}$ choline chloride, $11.6 \mathrm{mM} \mathrm{Na}$-ascorbate, $7 \mathrm{mM} \mathrm{MgCl}$, $3.1 \mathrm{mM}$ Na-pyruvate, $2.5 \mathrm{mM} \mathrm{KCl}, 1.3 \mathrm{mM} \mathrm{NaH}_{2} \mathrm{PO}_{4}, 0.5 \mathrm{mM} \mathrm{CaCl}_{2}, 26 \mathrm{mM}$ $\mathrm{NaHCO}_{3}, 10 \mathrm{mM}$ glucose, $\sim 300 \mathrm{mOsm}, \mathrm{pH}$ 7.4) that was continuously perfused with carbogen $\left(95 \% \mathrm{O}_{2}\right.$ and $\left.5 \% \mathrm{CO}_{2}\right)$. Coronal slices of $350 \mu \mathrm{m}$ thickness were retrieved using a using a vibrating-blade microtome (HM-650 V, ThermoScientific). Retrieved slices were placed in a holding chamber containing aCSF $\left(125 \mathrm{mM} \mathrm{NaCl} ; 3 \mathrm{mM} \mathrm{KCl} ; 1.2 \mathrm{mM} \mathrm{NaH}_{2} \mathrm{PO} 4 ; 1 \mathrm{mM} \mathrm{MgSO} 4 ; 2 \mathrm{mM} \mathrm{CaCl}_{2} ; 26 \mathrm{mM}\right.$ $\mathrm{NaHCO}_{3} ; 10 \mathrm{mM}$ glucose, $300 \mathrm{mOsm}$, pH 7.4), oxygenated with $95 \% \mathrm{O}_{2}, 5 \% \mathrm{CO}_{2}$. Slices were allowed to recover for $1 \mathrm{~h}$ following slicing.

Electrophysiology of acute slices. Whole-cell recordings were performed using an MultiClamp 700B amplifier (Molecular Devices) in a submerged holding chamber at room temperature under continuous superfusion of oxygenated $\left(95 \% \mathrm{O}_{2}\right.$ and $\left.5 \% \mathrm{CO}_{2}\right)$ aCSF. Digidata 1440A and Clampex 10.2 (Molecular Devices) were used for data acquisition. Recordings were sampled at $10 \mathrm{kHz}$ and low-pass filtered at $3 \mathrm{kHz}$. Borosilicate patch pipettes (resistance 2.5-4.5 M 2 ) were filled with intracellular solution $(148 \mathrm{mM} \mathrm{K}$-gluconate, $1 \mathrm{mM} \mathrm{KCl}, 10 \mathrm{mM}$ HEPES, $4 \mathrm{mM}$ Mg-ATP, $4 \mathrm{mM} \mathrm{K}$-Phosphocreatine, $0.4 \mathrm{mM}$ GTP, pH 7.4, $\sim 290 \mathrm{mOsm})$. Neurons were held in voltage-clamp at $-70 \mathrm{mV}$. Only cells with an access resistance of $<20 \mathrm{M} \Omega$ and leak current of $<100 \mathrm{pA}$ were accepted for analysis. Spontaneous events were analysed in MiniAnalysis software 6.0 (Synaptosoft, NJ, USA).

Immunocytochemistry. Cultures were fixed with 3.7\% formaldehyde (Electron Microscopy Sciences). After washing with PBS, cells were permeated with $0.1 \%$ Triton X-100 for $5 \mathrm{~min}$ and incubated in $2 \%$ normal goat serum for $20 \mathrm{~min}$ to block aspecific binding. Cells were incubated for $1 \mathrm{~h}$ at room temperature in a mixture of monoclonal mouse anti-VAMP $(1: 1,000$, SySy, 104204) or ant-syntaxin (1:1,000, SySy, 110402), polyclonal chicken anti-MAP2 (1:10,000, Abcam, ab5392) and polyclonal rabbit anti-Munc18-1 (1:500, SySy, 116003) antibodies. After washing, cells were incubated for $1 \mathrm{~h}$ at room temperature with second antibodies conjugated to Alexa dyes (1:1,000, Molecular Probes, A20180, A20186) and washed again. Coverslips were mounted with Mowiol-Dabco and imaged with a confocal LSM510 microscope (Carl Zeiss) using a $\times 40$ oil immersion objective with $\times 0.7$ zoom at $1,024 \times 1,024$ pixels. Neuronal morphology and protein levels were analysed using a published automated image analysis routine ${ }^{59}$.

Data availability. The data that support the findings of this study are available from the corresponding author upon reasonable request.

\section{References}

1. Sørensen, J. B. et al. Sequential N- to C-terminal SNARE complex assembly drives priming and fusion of secretory vesicles. EMBO J. 25, 955-966 (2006).

2. Stein, A., Weber, G., Wahl, M. C. \& Jahn, R. Helical extension of the neuronal SNARE complex into the membrane. Nature 460, 525-528 (2009).

3. Rizo, J. \& Südhof, T. C. Snares and munc18 in synaptic vesicle fusion. Nat. Rev Neurosci. 3, 641-653 (2002).

4. Sørensen, J. B. Conflicting views on the membrane fusion machinery and the fusion pore. Annu. Rev. Cell Dev. Biol. 25, 513-537 (2009).

5. Südhof, T. C. \& Rothman, J. E. Membrane fusion: grappling with SNARE and SM proteins. Science 323, 474-477 (2009).

6. van den Bogaart, G. et al. Membrane protein sequestering by ionic protein-lipid interactions. Nature 479, 552-555 (2011)

7. Rosenmund, C. et al. Differential control of vesicle priming and short-term plasticity by Munc13 Isoforms. Neuron 33, 411-424 (2002).

8. Toonen, R. F. G. et al. Munc18-1 expression levels control synapse recovery by regulating readily releasable pool size. Proc. Natl Acad. Sci. USA 103, 18332-18337 (2006).

9. Toonen, R. F. G. \& Verhage, M. Munc18-1 in secretion: lonely Munc joins SNARE team and takes control. Trends Neurosci. 30, 564-572 (2007). 
10. Jockusch, W. J. et al. CAPS-1 and CAPS-2 are essential synaptic vesicle priming proteins. Cell 131, 796-808 (2007)

11. de Jong, A. P. \& Verhage, M. Presynaptic signal transduction pathways that modulate synaptic transmission. Curr. Opin. Neurobiol. 19, 245-253 (2009).

12. Söllner, T. et al. SNAP receptors implicated in vesicle targeting and fusion. Nature 362, 318-324 (1993)

13. Schweizer, F. E. et al. Regulation of neurotransmitter release kinetics by NSF. Science 279, 1203-1206 (1998).

14. Zhao, M. et al. Mechanistic insights into the recycling machine of the SNARE complex. Nature 518, 61-67 (2015)

15. Trimbuch, T. \& Rosenmund, C. Should I stop or should I go? The role of complexin in neurotransmitter release. Nat. Rev. Neurosci. 17, 118-125 (2016).

16. Walter, A. M., Groffen, A. J., Sørensen, J. B. \& Verhage, M. Multiple Ca2 + sensors in secretion: teammates, competitors or autocrats? Trends Neurosci. 34, 487-497 (2011)

17. Voets, T. et al. Munc18-1 promotes large dense-core vesicle docking. Neuron 31, 581-592 (2001).

18. Weimer, R. M. et al. Defects in synaptic vesicle docking in unc-18 mutants. Nat. Neurosci. 6, 1023-1030 (2003).

19. de Wit, H. et al. Synaptotagmin-1 docks secretory vesicles to syntaxin-1/SNAP25 acceptor complexes. Cell 138, 935-946 (2009).

20. Gulyás-Kovács, A. et al. Munc18-1: sequential interactions with the fusion machinery stimulate vesicle docking and priming. J. Neurosci. 27, 8676-8686 (2007).

21. Wierda, K. D. B., Toonen, R. F. G., de Wit, H., Brussaard, A. B. \& Verhage, M. Interdependence of $\mathrm{PKC}$-dependent and $\mathrm{PKC}$-independent pathways for presynaptic plasticity. Neuron 54, 275-290 (2007)

22. Ma, C., Su, L., Seven, A. B., Xu, Y. \& Rizo, J. Reconstitution of the vital functions of Munc18 and Munc13 in neurotransmitter release. Science 339, 421-425 (2013)

23. Verhage, M. et al. Synaptic assembly of the brain in the absence of neurotransmitter secretion. Science 287, 864-869 (2000).

24. Stevens, C. F. \& Tsujimoto, T. Estimates for the pool size of releasable quanta at a single central synapse and for the time required to refill the pool. Proc. Natl Acad. Sci. USA 92, 846-849 (1995).

25. Xu, T. et al. Inhibition of SNARE complex assembly differentially affects kinetic components of exocytosis. Cell 99, 713-722 (1999).

26. Walter, A. M., Wiederhold, K., Bruns, D., Fasshauer, D. \& Sørensen, J. B. Synaptobrevin N-terminally bound to syntaxin-SNAP-25 defines the primed vesicle state in regulated exocytosis. J. Cell Biol. 188, 401-413 (2010).

27. Weber, J. P., Reim, K. \& Sørensen, J. B. Opposing functions of two sub-domains of the SNARE-complex in neurotransmission. EMBO J. 29, 2477-2490 (2010)

28. Varoqueaux, F. et al. Total arrest of spontaneous and evoked synaptic transmission but normal synaptogenesis in the absence of Munc13-mediated vesicle priming. Proc. Natl Acad. Sci. USA 99, 9037-9042 (2002).

29. Kuner, T., Li, Y., Gee, K. R., Bonewald, L. F. \& Augustine, G. J. Photolysis of a caged peptide reveals rapid action of $\mathrm{N}$-ethylmaleimide sensitive factor before neurotransmitter release. Proc. Natl Acad. Sci. USA 105, 347-352 (2008).

30. Morrell, C. N., Matsushita, K. \& Lowenstein, C. J. A novel inhibitor of $\mathrm{N}$-ethylmaleimide-sensitive factor decreases leukocyte trafficking and peritonitis. J. Pharmacol. Exp. Ther. 314, 155-161 (2005).

31. Durand, G. M., Kovalchuk, Y. \& Konnerth, A. Long-term potentiation and functional synapse induction in developing hippocampus. Nature 381, 71-75 (1996).

32. Tyzio, R. et al. The establishment of GABAergic and glutamatergic synapses on CA1 pyramidal neurons is sequential and correlates with the development of the apical dendrite. J. Neurosci. 19, 10372-10382 (1999).

33. Genc, O., Kochubey, O., Toonen, R. F., Verhage, M. \& Schneggenburger, R. Munc18-1 is a dynamically regulated PKC target during short-term enhancement of transmitter release. eLife 3, e01715 (2014)

34. Weis, S., Schneggenburger, R. \& Neher, E. Properties of a model of $\mathrm{Ca}++-$ dependent vesicle pool dynamics and short term synaptic depression. Biophys. J. 77, 2418-2429 (1999).

35. Pan, B. \& Zucker, R. S. A general model of synaptic transmission and shortterm plasticity. Neuron 62, 539-554 (2009).

36. Basu, J., Betz, A., Brose, N. \& Rosenmund, C. Munc13-1 C1 domain activation lowers the energy barrier for synaptic vesicle fusion. J. Neurosci. 27, 1200-1210 (2007).

37. Schotten, S. et al. Correction: additive effects on the energy barrier for synaptic vesicle fusion cause supralinear effects on the vesicle fusion rate. eLife 4, e09036 (2015).

38. Taschenberger, H., Woehler, A. \& Neher, E. Superpriming of synaptic vesicles as a common basis for intersynapse variability and modulation of synaptic strength. Proc. Natl Acad. Sci. USA 113, E4548-E4557 (2016)
39. Mohrmann, R., de Wit, H., Verhage, M., Neher, E. \& Sørensen, J. B. Fast vesicle fusion in living cells requires at least three SNARE complexes. Science 330, 502-505 (2010).

40. Ishiyama, S., Schmidt, H., Cooper, B. H., Brose, N. \& Eilers, J. Munc13-3 superprimes synaptic vesicles at granule cell-to-basket cell synapses in the mouse cerebellum. J. Neurosci. 34, 14687-14696 (2014)

41. Liu, X. et al. Functional synergy between the Munc13 C-terminal C1 and C2 domains. eLife 5, e13696 (2016).

42. Dinkelacker, V., Voets, T., Neher, E. \& Moser, T. The readily releasable pool of vesicles in chromaffin cells is replenished in a temperature-dependent manner and transiently overfills at $37^{\circ} \mathrm{C}$. J. Neurosci. 20, 8377-8383 (2000).

43. Delvendahl, I., Weyhersmüller, A., Ritzau-Jost, A. \& Hallermann, S. Hippocampal and cerebellar mossy fibre boutons - same name, different function. J. Physiol. 591, 3179-3188 (2013).

44. Millar, A. G., Bradacs, H., Charlton, M. P. \& Atwood, H. L. Inverse relationship between release probability and readily releasable vesicles in depressing and facilitating synapses. J. Neurosci. 22, 9661-9667 (2002).

45. Chang, C. C., Lu, S. E., Wang, P. N. \& Chuang, S. T. A comparison of the effects of various sulfhydryl reagents on neuromuscular transmission. Eur. J. Pharmacol. 11, 195-203 (1970).

46. Carmody, J. J. Enhancement of acetylcholine secretion by two sulfhydryl reagents. Eur. J. Pharmacol. 47, 457-460 (1978).

47. Carlson, C. G. \& Dettbarn, W. D. The aminoglycoside antibiotic, gentamicin, fails to block increases in miniature endplate potential frequency induced by the sulfhydryl reagent, N-ethylmaleimide, in low calcium solutions. Brain Res. 330 , 349-352 (1985)

48. Varoqueaux, F., Sons, M. S., Plomp, J. J. \& Brose, N. Aberrant morphology and residual transmitter release at the Munc13-deficient mouse neuromuscular synapse. Mol. Cell Biol. 25, 5973-5984 (2005).

49. Gioia, D. A., Alexander, N. J. \& McCool, B. A. Differential expression of Munc13-2 produces unique synaptic phenotypes in the basolateral amygdala of C57BL/6 J and DBA/2 J mice. J. Neurosci. 36, 10964-10977 (2016).

50. Breustedt, J. et al. Munc13-2 differentially affects hippocampal synaptic transmission and plasticity. Cereb. Cortex 20, 1109-1120 (2010).

51. Schoch, S. et al. RIM1 $\alpha$ forms a protein scaffold for regulating neurotransmitter release at the active zone. Nature 415, 321-326 (2002).

52. Liu, K. S. Y. et al. RIM-binding protein, a central part of the active zone, is essential for neurotransmitter release. Science 334, 1565-1569 (2011).

53. Deng, L., Kaeser, P. S., Xu, W. \& Südhof, T. C. RIM proteins activate vesicle priming by reversing autoinhibitory homodimerization of Munc13. Neuron 69, 317-331 (2011)

54. Yang, Y. \& Calakos, N. Munc13-1 is required for presynaptic long-term potentiation. J. Neurosci. 31, 12053-12057 (2011)

55. Kawabe, H. et al. ELKS1 localizes the synaptic vesicle priming protein bMunc13-2 to a specific subset of active zones. J. Cell Biol. 216, 1143-1161 (2017).

56. Rizo, J. \& Xu, J. The synaptic vesicle release machinery. Annu. Rev. Biophys. 44, 339-367 (2015)

57. Augustin, I., Rosenmund, C., Südhof, T. C. \& Brose, N. Munc13-1 is essential for fusion competence of glutamatergic synaptic vesicles. Nature 400, 457-461 (1999).

58. Bekkers, J. M. \& Stevens, C. F. Excitatory and inhibitory autaptic currents in isolated hippocampal neurons maintained in cell culture. Proc. Natl Acad. Sci. USA 88, 7834-7838 (1991)

59. Schmitz, S. K. et al. Automated analysis of neuronal morphology, synapse number and synaptic recruitment. J. Neurosci. Methods 195, 185-193 (2011).

\section{Acknowledgements}

We thank Robbert Zalm for expert help with cloning and virus production, Desiree Schut for preparing glia feeders and culturing neurons; and Frank den Oudsten, Erik Ceelen, Joost Hoetjes, Joke Wortel, Christiaan van der Meer for breeding and genotyping mutan mice. We thank Dr S. van der Sluis for suggestions regarding statistical testing, Prof Nils Brose (Göttingen) for sharing munc13-1/2 and CAPS1/2 null mice, Prof Phyllis Hanson for valuable advice on NSF-interfering strategies and Prof Thomas Kuner (Heidelberg) for advice on NEM-interfering peptides. This work is supported by the European Union (ERC Advanced grant 322966; HEALTH-F2-2009-241498 EUROSPIN, and HEALTHF2-2009-242167 SynSys to M.V.).

\section{Author contributions}

E.H., L.N.C. and M.V. designed the research. E.H. performed most electrophysiology and all histology. K.W. and L.N.C. performed the initial electrophysiology on munc18-1/2SWAP neurons. K.W. performed ultrastructural morphometry. R.v.W. performed all the slice recordings. R.F.T. supervised/optimized cell biology and neuronal cultures. E.H., K.W., J.H.B. and L.N.C. analysed the data. E.H. and M.V. wrote the paper with input of all authors. 


\section{Additional information}

Supplementary Information accompanies this paper at http://www.nature.com/ naturecommunications

Competing interests: The authors declare no competing financial interests.

Reprints and permission information is available online at http://npg.nature.com/ reprintsandpermissions/

How to cite this article: He, E. et al. Munc13-1 and Munc18-1 together prevent NSF-dependent de-priming of synaptic vesicles. Nat. Commun. 8, 15915 doi: $10.1038 /$ ncomms15915 (2017).

Publisher's note: Springer Nature remains neutral with regard to jurisdictional claims in published maps and institutional affiliations. cc (i) Open Access This article is licensed under a Creative Commons Attribution 4.0 International License, which permits use, sharing, adaptation, distribution and reproduction in any medium or format, as long as you give appropriate credit to the original author(s) and the source, provide a link to the Creative Commons license, and indicate if changes were made. The images or other third party material in this article are included in the article's Creative Commons license, unless indicated otherwise in a credit line to the material. If material is not included in the article's Creative Commons license and your intended use is not permitted by statutory regulation or exceeds the permitted use, you will need to obtain permission directly from the copyright holder. To view a copy of this license, visit http://creativecommons.org/ licenses/by/4.0/

(C) The Author(s) 2017 